DOI https://doi.org/10.18551/rjoas.2020-11.26

\title{
INFORMED CONSENT AS A REFLECTION OF PHYSICIAN'S ACCOUNTABILITY
}

\author{
Widoretno Heristiawati Sekar* \\ Master's Program in Accounting, Faculty of Economics and Business, \\ University of Brawijaya, Indonesia \\ Irianto Gugus, Ghofar Abdul \\ Faculty of Economics and Bussines, University of Brawijaya, Indonesia \\ *E-mail: heristiawatisekarw@gmail.com
}

\begin{abstract}
Accountability has various interpretations. In general, accountability linked with the relationship between two or more parties, where one party provides the mandate while the other party carries out the mandate and is accountable for it. The substance of the accountability can be in the form of financial and non-financial aspects. In the world of accounting, accountability focuses on financial aspects. This is different from that in the world of health, in particular what doctors do. This research serves to explore the accountability of doctors. This research is a qualitative descriptive study using Husserl's transcendental phenomenology approach and is in the realm of the interpretive paradigm. Data were collected trough in-depth interview and observation. This study found that doctor's accountability reflected in informed consent, which is consent given by the patient after the doctor's explanation and information is provided. There are 3 (three) main components of doctor's accountability reflected in informed consent, consisting of (1) professionalism, (2) transparency, and (3) best treatment.
\end{abstract}

\section{KEY WORDS}

Accountability, informed consent, health, physician, patient.

Doctors who set challenging income objectives may become less faithful agents for their patients, say by reducing their time per visit or refusing to treat uninsured patients. (Rizzo and Zeckhauser, 2007).

Medical profession is consistently seen as a noble profession that promotes humanity. But in fact, just like any other economic agents, doctors also respond positively to financial incentives (Croxson and Perkins, 2001; Dusheiko et al., 2006). As the findings of Lester et al. (2010) revealed that doctors tend to reduce the volume of medical services when there is a reduction in incentives by the hospital. This point is critically explained by Rizzo and Zeckhauser (2007) in the quote above. Rizzo and Zeckhauser view that doctors who place high income as their main goal, then when there is a reduction in incentives, doctors will have a tendency to reduce visiting hours or refuse to treat patients who do not have health insurance. Doctors are agents who are responsible for their patients. But when faced with a financial situation that specifically involves incentives, doctors may be less trustworthy agents. It is understandable because doctors are also human beings who also have to fulfill their needs and being a doctor requires hard effort and a lot of material capital. But unfortunately, this is realy contrast because the image of the doctor profession is known as a party that places the needs of patients as top priority and bases its services on the conscience (Buamona, 2015: 3). This condition illustrates the dualism experienced by a doctor. This has actually been worried by Chua and Preston (1994) who explained that accounting has a bad influence on the world of health care. Accounting, which we know is all about profit and loss, is in fact able to influence the delivery of health services.

The world of accounting is closely related to accountability. Accountability has so far been associated with financial-related organizations. But in fact, accountability also plays an 
important role in the health system, especially if it is related to hospital performance as a socio-economic organization (Brinkerhoff, 2003: v). There are many articles that discuss accountability in the health system, such as articles written by Kennedy, Didehban \& Fasolino (2014), Yeager, Zhang \& Diana (2015), Bakalikwira, et al., (2017), and Genovese, et al.(2017). Overall, these articles state that the hospital places patient satisfaction as its main goal. This makes the accountability component of the health system very complex and extensive. The financial perspective alone cannot be a major component. Other aspects besides finance must also receive attention. One aspect that also important to be understood is the doctor's accountability. The dualism experienced by this doctor is more or less able to raise questions about a doctor's accountability.

The reason for choosing a doctor as the center of this research instead of another profession or hospital organization was based on the thoughts of Jacobs, Marcon \& Witt (2004) and Sari (2014) who stated that doctors are a central figure in the world of health. As a central figure who has direct contact with and direct responsibility for patients, the search for accountability from doctor's perspective is appropriate to be investigated more deeply.

\section{METHODS OF RESEARCH}

This research was a qualitative research with an interpretive paradigm and a phenomenological approach. The aim of research with a phenomenological approach is to understand in depth about the studied object. The phenomenology referred to is the phenomenology coined by Edmund Husserl, namely transcendental phenomenology (Husserl: 1978). Transcendental phenomenology is a study used to explore individual subjective experiences, containing elements of deliberation, extracting implicit meaning, and focusing on one's experiences (Kamayanti, 2016).

The informants in this study consisted of three specialist doctors who had experience as a specialist for more than 10 (ten) years. One of the three informants is a medical faculty professor at a public university. Accountability is closely related to ethics and law. What is unique about these three informants is that they have studied the ethical and legal aspects of medicine by taking courses in law and medical ethics. These aspects are the main considerations for researchers in selecting the three informants.

The data were collected through observation and in-depth interviews methods. In-depth interviews in this study are referred to as the term epoche. Epoche is a process of postponing researchers' decisions on the information described by informants (Moustakas, 1994). The data analysis technique used was the sequence adopted from Edmund Husserl (Husserl, 1978), namely noema, epoche, noesis, intentional analysis, intuition, eidetic reduction.

The noema in this study implies the doctors' initial expressions about the doctor's accountability to patients conveyed by the research informants. Every word or sentence in the expression conveyed by the informant were tried to be understood by the researcher by paying attention to intonation and expression which will then be led to noesis. This Noema will later be used as a basis for revealing and collecting further information through the epoche. Epoche is carried out by the researcher when the informant has stated an initial statement or opinion (noema) about the doctor's accountability to the patient by following the noema-epoche pathway to find noesis. This process is carried out until it reaches the saturation point. This is because in the epoche process, it is very possible to continue to generate new noesis. The purpose of saturation here is when the data obtained and collected is able to answer the researcher's questions. The noesis in this study is the informant's opinion about the doctor's accountability to patients, which is pure awareness conveyed through the epoche stage. The deeper the researcher explores the noema, the clearer the noesis will be. After that, the researcher conducted an intentional analysis which refers to awareness based on experience, so that the intentional will be more meaningful as an awareness of the object. Intensional analysis in this study is the informant's reason (expressed through noema-noesis) for understanding accountability. Intuition is carried out 
when researchers carry out the process of gathering information from informants. The intuition referred to is the researcher's ability to understand informants' statements without going through rational reasoning, but rather to an understanding that emerges suddenly. Intuition is also better known as a whisper or heart movement. Eidetic reduction is the process of combining ideas from the entire process of meaning that has been done. It can also be said that eidetic reduction is the idea that underlies the overall awareness of the research informants.

\section{RESULTS OF STUDY}

Accountability is an abstract concept. Many researchers define accountability according to their versions, but the substance is not far from being accountable for the actions taken, either individually or in an organization. As the World Health Organization (WHO) explains, accountability is described as a relationship between the one who gives a mandate and the one who holds the mandate. It describes the capacity to sue a person or organization to provide reasons that justify their behavior and provide the capacity to impose sanctions if they fail to provide reasons, or if their performance is poor. It is the same as described by Emmanuel (1996) who explained that accountability is the obligation of one party to provide justification and accountability for its actions to other interested parties. Based on these two statements, it is concluded that accountability is a relationship that exists between the party who is given the responsibility and the party who accepts the responsibility in order to carry out that responsibility properly and deserves any consequences according to what he does.

In the world of health, doctors have a central role in providing health services to patients. Therefore, the patient is the party most entitled to receive the responsibility of a doctor for all treatments taken on him. This is as explained by dr. Is as follows:

"...Patients deserve to receive information from a doctor and have the right to receive optimal care from a doctor. The patient has the right to know the potential risks, benefits and alternative treatments in a medical procedure that will be carried out on him. This function also protects patient autonomy. The doctor has an obligation and responsibility to explain all the treatments he takes to his patients. It's a doctor's responsibility."

That statements explained by $\mathrm{dr}$. Is reveals that the patient has the right to know all treatments that are carreid out on him. This is also often understood in terms of autonomy, as explained by dr. Is. As a human being, a patient has the fundamental right to be treated well by anyone, especially by a doctor. In addition, patients also have the right to determine and choose what is good for them. Thus, consequently, a doctor is obliged to respect this right by providing all information regarding what treatments he has taken against a patient. In addition to delivering good information, maximum handling is also a form of a doctor's responsibility to the patient. Considering that the point of accountability itself is the obligation of one party to provide answers and information and explanations in order to be accountable for his treatments to other parties, then the accountability of a doctor to a patient can be seen from how the delivery of information relating to the treatments he takes and all the efforts made in treating a patient.

A patient who feel sicks or has disease symptoms will go to a doctor who is considered capable of curing his illness. Likewise, when there is a hit and run victim, they will immediately be rushed to the Emergency Room for getting immediate treatment from a doctor. The patient realizes that if he is sick, he will choose to come to the doctor and is willing to be treated and handled by the doctor in order to recover as before. These conditions indicate that a patient with complaints of illness will "surrender" himself voluntarily to receive medical treatment from a doctor because he knows that the doctor has the ability to make himself well. Even though a patient has autonomy over himself and has the right to determine and approve all treatments taken by a doctor to him, the doctor is still obliged to convey the information he knows to a patient before taking medical treatments against him. This is due to a knowledge gap where a doctor has in-depth knowledge of a patient's illness, while a patient has minimal knowledge of it. Therefore, before a patient consciously agrees 
to any treatments taken against him, it is necessary to communicate information by a doctor to the patient.

Everything related to the information needed by the patient and the delivery of information from a doctor to the patient is reflected in a "consent contract" made between the doctor and the patient which is called informed consent. More clearly related to this informed consent can be seen in the statement delivered by dr. Is as follows:

"Informed consent is the consent given by the patient after getting explanation that is understood by the patient without coercion, without threats, and without persuasion or deception. "Understood" is a word to be aware of. Communication skills are the main key."

This was later clarified once more time by a statement from dr. Ret in the following statement:

"Informed consent is an agreement. That is the point. Besides, there is also an agreement between the doctor and the patient. The terms of the agreement are that there must be an agreement, skills, special matters, and it must be detailed. Therefore, the explanation must be in detail, for example if a surgery should be performed, it must be explained what kind of surgery, how is the procedure, the steps will be taken, that the bones will be taken, will be stored, and after the surgery is done, then here [refers to certain body parts] will have no bone, all must be explained in the informed consent."

The explanation stated by $\mathrm{dr}$. Is and dr. Ret explained that informed consent was an consent given by a patient to a doctor to allow the doctor to take medical treatments on him after being given all the information related to his condition and treatments to be taken in the future along with the risks and costs. This is also consistent with the definition of informed consent by several previous researchers (Kirby, 1983; Graber \& Tansey, 2005; Nijhawan, et al., 2013). It should also be underlined that a patient must be understood in advance about all the conditions in him or about whatever the doctor will do to him considering this is a form of respect for the autonomy of a patient by a doctor. Of course, many medical terms may not be understood by patients because of knowledge gaps. Therefore, the doctor should explain in the simplest language so that it is easily understood by the patient. This communication is important in building a good relationship between doctor and patient. The autonomy of a patient makes the patient have the right to approve or reject all treatments that the doctor will do on him. If the patient refuses, the appointment may be renewed or it may be canceled. However, if the patient agrees to the treatments that the doctor will take on him, then a relationship and contract is established between the doctor and the patient. This is indicated by the signing of informed consent by the patient.

An incident in a patient who came to the doctor because his hand was cut by a knife with a patient who had a heart defect but had to give birth, surely the handling given would be different. For this reason, the type of informed consent is also different, as explained by dr. Set:

"Informed consent can be in the form of verbal or written forms and implied. Informed consnt in the form of verbal is carried out if the treatment has low risk, for example when the patient needs to be fitted with a catheter, and if the patient agrees by answering "yes please", then the doctor can do the treatment. In contrast to high-risk treatments, such as uterine surgery, written informed consent is needed and it needs to be explained in simply language, if it is agreed, then the patient can sign the informed consent. "

According to dr. Set, Informed consent has three types, namely written informed consent, verbal and imppied. The administration of the three is differentiated based on the risk of treatment that will be given by the doctor to the patient. If the patient comes only to have blood drawn or to have a catheter inserted, the doctor can simply provide an explanation or through dirrect communication can even use gestures, for example by nodding. This is a sign of a patient's consent if he is willing that the doctor does the medical treatment to him. It is different with medical procedures with high risks, such as surgery for pregnant women whose babies have to be born with cesarean delivery or surgical removal of tumors in the brain that require doctors to drill and perforate the skull In such cases, written informed consent is required. Given that the treatments to be carried out by a doctor have a high risk, this is where informed consent plays an important role. Informed consent is not just 
proof of agreement with the doctor's treatment against the patient, but more than that, patients can understand the various possibilities that will happen to them through the informed consent. Written informed consent provided before a high-risk medical procedure contains detailed information that patients need to know before treatment is carried out. This is as stated by dr. Is in the quote as follows:

"The contents of diagnosis consent are the diagnosis, the treatment will carried out, the risks and alternatives to the treatment, the alternative risks, the risks if the treatment is not performed (the treatments described earlier), and the estimated costs that will be charged to the patient, as well as the hope of a cure. If the IC, the explanation should cover all steps will be carreid out. For example is a tumor. The diagnosis of tumor is kind like this, conditions that might be happened also needs to be explained. How is the anesthesia process and the risks of anesthesia. Then if the blood pressure is 170, there could be a stroke and must be treated in the ICU. All that must be explained to the patient."

When a patient undergoes a medical check up, the doctor can find out what symptoms the patient has. By all the knowledge and experience they have, the doctor can also find out what disease the patient is suffering from, what treatments are needed to cure him, what are the risks that might occur, whether there is no treatment or treatment, as well as what the patient's condition might be if the treatment is taken and the last is the estimated cost that will be charged to the patient if the treatment has been approved to be carried out. This set of information is written in the informed consent. It is the doctor's responsibility to explain and convey this to the patient in detail and in an words that is easy to understand. However, there are several conditions that require a doctor's empathy and caution in conveying information, as explained by dr. Set as follows:

'If there is a risk the patient could be die, the doctor must also explain it carefully. The explanation given must not be explicit, because it may cause anxiety."

This is why good communication skills are very important in explaining the contents of informed consent. Indeed, doctors are obliged to convey in detail and clearly, but there are things that must be conveyed carefully, considering the patient's condition and the patient's family as well. Likewise, for the information on possible conditions after the procedure, doctors should not over-promise regarding the patient's recovery. This is as stated by doctor Is as follows:

"About the prognosis [the possible conditions the patient will experience after the procedure; the possibility of a patient's recovery], we also cannot guarantee that there will be a cure, because full healing comes from the power of God."

In an informed consent agreement, it is not "cure" that is guaranteed by the doctor, but "the best treatment can be given". Prognosis information in informed consent must be within reasonable limits. Doctors should not give the patient too high expectations. As explained by dr. Is who stated that the patient's healing is God's will. Doctors only act as a connector for God's hands.

Then what about the patient who is admitted to the hospital in unconscious condition? or are aware but the condition makes it impossible to ask for informed consent? In this condition, the party that has the right to be given information and asked for consent is the patient's family. Similar to a patient who is aware, the family of a patient who is not aware or cannot provide information and is asked for consent has the right to replace the patient in receiving information and giving consent. This is as expressed by dr. Ret as follows:

"Actually, it is also for patient safety. So, for example IC [Informed Consent] reaches cases that require removal of the uterus, or want to be sterile, so that the impact is that she cannot have any more offspring, so it is her husband must sign it. But if it's a cesarean section or something, it doesn't have to be the husband, because in that case it's not related to heredity. So in case there is an emergency, there are rules in it. If in a very emergency situation, for example the uterus must be removed, then the presence of her husband is very necessary, along with the patient's family."

The next point is emphasized and clarified by the statement of $\mathrm{dr}$. Is is as follows:

"For example, this patient has a heart disease, but she also has to undergo a cesarean section, it will make her nervous, for example, with a worrisome heart condition, so once 
sedated, she could die before the surgery. In such cases, we usually communicate informed consent completely and concurrently. The whole family must listen to the doctor's explanation, at least if it is not possible, then it must be more than one family member. In this case, the surgeon and the anesthetist will explain together. For example, explained from a surgical perspective, "so the treatment to be carried out is kind of like this with these risks which might make the patient die even when anesthetized just get started".

Each high-risk case handled by a doctor has different condition from one another which causes the handling of one patient to another patient is also different. In cases that have a high risk, as explained by dr. Ret and dr. Is, there may be a condition where the patient cannot decide on his own or give consent regarding the treatments that the doctor will take on him. For this reason, the presence of the family in making decisions is very important. Through informed consent, doctors and patients or their families can exchange information about all matters relating to the patient's condition. This is done so that the patient or the patient's family can understand and know all the possibilities that may occur after the treatment taken by the doctor.

Another aspect is the financial aspect. Financial acpect is also important and needs to be informed and explained further to the patient or patient's family. This is as stated by dr. Ret:

"These patients will also obtain an explanation of the costs through informed consent, they can find out what kind and the amount will be charged."

There are differences in the financial condition between one patient and another patient. This then becomes a consideration for the preparation of treatments to be carried out on the patient. Any treatments that the doctor will take on the patient also affect the amount of costs charged to the patient. Conversely, all treatments that will be taken by the doctor on the patient also depend on the budget agreed by the patient. If the patient has an adequate financial condition, then the patient tends to choose the best treatment and medical tools. This is different with patients whose financially is low. They tend to choose medical treatments and devices according that they can afford. Thus, communication about the cost is also an important thing to explain before any treatment by a doctor is carried out. As explained by dr. Set in the following statement:

"... About costs are also included. For example, from the beginning the patient will be asked whether he is using assurance or not? Or does he has other insurance? Then the answer is, "No. I have no assurance", for example. In the middle of the treatment process, the patient says "Does it cost this much? Then it would be beeter if I use assurance." Well, there should be an agreement at the beginning.

Which explained deeply by dr. Is as follows:

"... Estimates about costs have also been informed in informed consent. This is because some patients ask about the costs he has to spend for the medical treatment. There are also those who because of high costs especially for planned operations, then they delay or cancel the surgery. He may refuse, and choose another way. He may find out how much it will cost. Through an informed consultation, he can ask all matters related to medical treatment to his doctor."

This communication of costs is intended so that the patient understands what he will get from a number of costs that are charged to him, related to all treatments and medical devices needed in handling. In this communication, it is possible to have a "bargain" between the patient and the doctor, so that the patient can choose to agree to what treatments or tools are used in medical treatment on him. As explained by dr. Set, of course there will be a difference in costs between patients who use assurance and patients who do not. All can be adjusted through the explanation of informed consent. On the other hand, doctors are a noble profession that prioritizes humanity more than just the financial aspect. Unlike the world of economics which puts forward material, maximizing treatment is the main focus of a doctor. For patients who use assurance, maximization of treatment still must be applied because obtaining maximum medical treatment is the right of each patient regardless of their financial condition. 
After the doctor explains all aspects to the patient, both non-financial and financial aspects, it will arrive for the patient to determine whether he agrees to take the medical treatment or not. If the patient agrees, the doctor will begin to perform the treatments previously explained to the patient. However, it needs to be emphasized once again that what the doctor promised was not certainty of the patient's "cure", but "maximization of effort". This is because healing is $100 \%$ God's will. Maximization of effort also means efforts to avoid risk. Apart from all the maximum efforts that have been made by the doctor, all possibilities may happen which depends on the patient's condition during the procedure and after the procedure. In this case the possibility for further treatment might be taken. When further treatment is required, the doctor is also obliged to compile a new informed consent regarding the follow-up treatment to be given, including the fees that will be charged. This is as explained by $\mathrm{dr}$. Is in the following statement:

"If after a treatment has been taken, a follow up treatment is needed, it will automatically affect the treatments to be taken along with the costs. It will also be informed to the patient. Follow up treatment in this case will be explained."

As with the delivery of informed consent at the beginning, when the patient has consented, further treatment can be taken immediately.

\section{DISCUSSION OF RESULTS}

Several points were found as the key elements in describing the doctor's accountability to patients based on the results of the study, both financially (determining the costs borne by the patient based on consent) and non-financially (determining the treatments to be taken on the patient). The three key elements are "professionalism", "transparency" and "maximization of effort". These three aspects are related to one another and as a whole are reflected in informed consent.

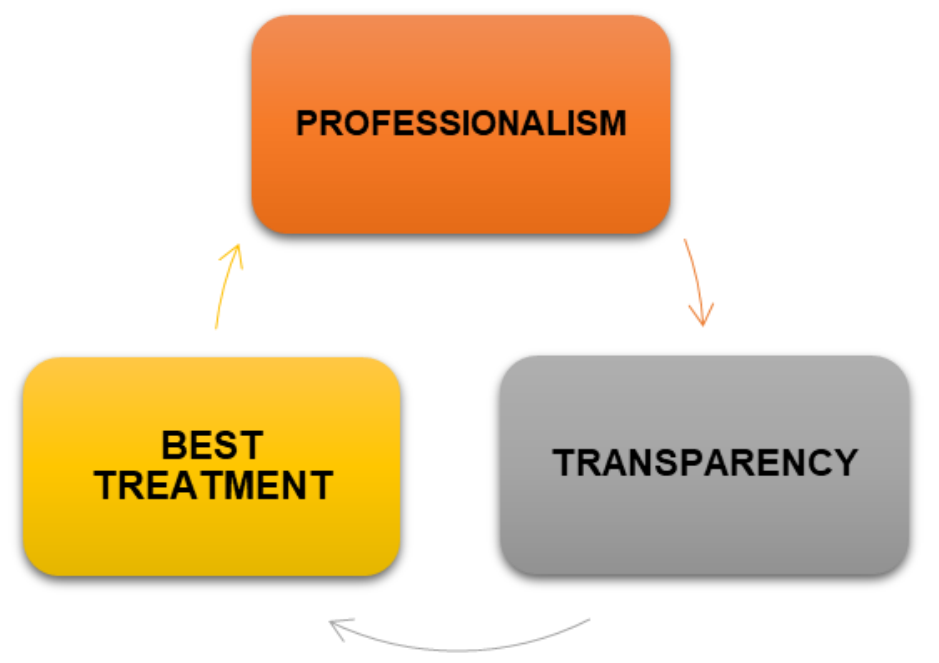

Figure 1 - Key elements of Physicians Accountability

Professionalism means the use of communication, knowledge, technical skills, clinical reasoning, emotions, values, and reflection in daily practice in a habitual and wise manner for the benefit of individuals and the community being served (Epstein, 2002). Professionalism is the first key element that reflects the doctor's accountability to patients. All the series performed by doctors, from patient examination, disease diagnosis, preparation of treatment processes, preparation of risk considerations, compiling possible conditions after the procedure, to communicating costs is a complex and long series. This series of activities cannot be carried out by people without expertises. It requires qualified skills, knowledge and experience. A doctor, especially a specialist in a professional manner should have ability to compile an informed consent appropriately according to the condition experienced by a patient. Therefore, professionalism is the first key element in physician accountability. 
The second key element is transparency. Transparency in healthcare is not only about the price or costs charged to patients, but also about outcomes, access, processes, sharing of information and knowledge at a level that is understandable to patients and their families. As explained in the subtitles that discusses the results of the study, patients and their families have the right to be given information and the right to give consent. Delivering all information contained in the informed consent from doctors to patients is a form of transparency. Transparency is a key element that is important in the accountability of a doctor.

Furthermore, the third key element is best treatment. After the consent of the patient and the patient's family for all treatments taken by the doctor is obtained, the doctor with all his efforts will take the optimum and best possible treatment. The maximization of this treatment is related to risk avoidance where caution is needed so that the patien's recovery can be quickly.

\section{CONCLUSION}

Doctor's accountability is reflected in an agreement contract between the doctor and patient called informed consent. Informed consent describes consent regarding the treatments that the doctor will take against the patient, given by the patient after getting an explanation that the patient can understand without coercion, without threats, and without persuasion or deception. Written informed consent is required before a doctor takes any major risky treatments. Written informed consent contains detailed information related to disease indications, disease diagnosis, treatments to be taken by doctors, risks, possible cure, and estimated costs. All such information must be conveyed and communicated by the doctor to the patient or patient's family and aims to respect the autonomy of the patient and the patient's family. Through informed consent, the accountability of a doctor can be known.

There are three key elements of doctor's accountability, namely: (1) professionalism; (2) transparency; and (3) maximization of treatment. The professionalism of doctors is reflected in the examination of the patient, the preparation of each item in the informed consent, to the execution of medical treatments. Not just anyone can do this. It takes appropriate knowledge, experience, emotional skills, and ethics to make informed consent. Professionalism is important in doctor's accountability. Next is transparency. The patient has the right to get information as clearly as possible about anything that will be done to him, and the right to approve or reject any treatment taken against him. Doctors have an obligation to convey and explain information both related non-financial and financial in detail, to the patient and the patient's family. The information conveyed must be as clear as possible in a language that most people can understand so that the patient knows and understands whatever will be done to him. Transparency is a key element in physicians' accountability to patients. The final key element is treatment maximization. A "guaranteed cure" is not what a doctor can promise you. Doctors can only promise "maximum effort", because healing is $100 \%$ God's. Therefore, after the patient consents, the doctor is obliged to make every effort, avoid risks, and be careful in his treatments. These three key elements are the essence of physician accountability.

\section{REFERENCES}

1. Bakalikwira, et al. 2017. Accountability in the Public Health Care Systems: A Developing Economy Perspective. Cogent Business \& Management, 4: 1334995.

2. Brikenhoff. Accountability and Health Systems: Overview, Framework, and Strategies. 2003. Bethesda, MD: The Partners for Health Reformplus Project, Abt Associates Inc.

3. Croxson B. Perkins A. 2001. Do Doctors respond to Financial Incentives? UK Family Doctors and the GP Fundholder Scheme. Journal of Public Economics Vol. 79 No. 2 pp. 375-398.

4. Chua, W. F. and A. Preston. 1994. Worrying about Accounting in Health Care. Accounting, Auditing and Accountability Journal Vol. 7 No. 3 PP 4-17. 
5. Dumont E., Fortin B., Jacquement N., Shearer B. 2008. Physicians' Multitasking and Incentives: Empirical Evidence from Natural Experiments. Journal of Health Economics Vol. 27 No. 6: 1436-1450.

6. Dusheiko M, Gravelle H, Jacobs R, Smith P. 2006. The effect of financial incentives on gatekeeping doctors: Evidence from a natural experiment. Journal of Heath Economics 25: 449-478.

7. Emanuel LL. A professional response to demands for accountability: practical recommendations regarding ethical aspects of patient care. Working Group on Accountability. Ann Intern Med 1996; 124: 240-9.

8. Epstein RM, Hundert EM. Defining and assessing professional competence. JAMA 2002;287(2): 226-235.

9. Genovese, et al. 2017. A New Paradigm on Health Care Accountability to Improve the Quality of The System: Four Parameters to Achieve Individual and Collective Accountability. Journal of Global Health, vol. 7 no. 1 pp: 1-4.

10. Graber MA, Tansey JF Autonomy, consent, and limiting healthcare costs Journal of Medical Ethics 2005; 31: 424-426.

11. Husserl, E. 1978. "The Crisis of European Science and Transendental Phenomenology: An Introduction to Phenomenology Philosopy". Trans. David Carr. Evanston. Northwestern University Press.

12. Kamayanti, A. 2016. "Metodologi Penelitian Kualitatif Akuntansi. Pengantar Religiositas Keilmuan". Cetakan pertama. Yayasan Rumah Peneleh. Jakarta Selatan.

13. Kennedy, Denise M., Didehban, Roshanak, \& Fasolino, John P. 2014. Creating and Sustaining a Culture of Accountability for Patient Experience. Patient Experience Journal, Vol. 1, No. 2, pp. 46-52.

14. Kirby, M D. Informed consent: what does it mean? Journal of Medical Ethics, 1983, 9, 69-75.

15. Lester H., Schimittdiel J., Selby J et. al.,. 2010. The Impact of Removing Financial Incentives from Clinical Quality Indicators: Longitudinal Analysis of Four Kaiser Permanente Indicators. British Medical Journal PP 340.

16. Moustakas, C. 1994. "Phenomenological Research Method". SAGE Research Methods. Online ISBN: 1981412995658 DOI: 10.4135/9781412995658. Pages 1-25.

17. Nijhawan LP, Janodia MD, Muddukrishna BS, Bhat KM, Bairy KL, Udupa N, Musmade PB. Informed consent: Issues and challenges. J Adv Pharm Tech Res 2013; 4: 134-40.

18. Rizzo, John and Zeckhauser, Richard. 2007. Pushing Incomes to Reference Points: Why Do Male Doctors Earn More?. Journal of Economic Behavior \& Organization. 2007. Vol. 63 no. 3 pp 514-536.

19. Sari, Dian P. 2014. Apa Makna Keuntungan Bagi Profesi Dokter? Jurnal Akuntansi Multiparadigma Vol. 5 No. 1 PP 130-138.

20. World Health Organization (WHO). Health Laws and Universal Health Coverage. https://www.who.int/health-laws/topics/governance-accountability/en/.

21. Yeager VA, Zhang Y \& Diana ML. 2015. Analyzing Determinants of Hospitals' Accountable Care Organizations Participation: A Resource Dependency Theory Perspective. Med Care Res Rev Vol. 72 no. 6 pp: 687-706. 